\title{
MANUAL DE GESTÃO DA RESERVA TÉCNICA SOB A SALVAGUARDA DO LEPAARQ - UFPEL
}

\author{
Rafael Guedes Milheira ${ }^{1}$ \\ Luciana da Silva Peixoto ${ }^{2}$ \\ Karen Velleda Caldas ${ }^{3}$ \\ Paula de Aguiar Silva Azevedo ${ }^{4}$
}

\section{RESUMO}

Este texto apresenta o manual de procedimentos adotados pelo Laboratório de Ensino e Pesquisa em Antropologia e Arqueologia da Universidade Federal de Pelotas (LEPAARQUFPEL), relativo à gestão das coleções depositadas na Reserva Técnica (RT) sob salvaguarda desta instituição. Os procedimentos de gerenciamento das coleções envolve, desde a sua entrada no ambiente do LEPAARQ, ações relacionadas à etapa de curadoria (higienização, marcação, acondicionamento, armazenamento, elaboração de banco de dados e documentação), assim como procedimentos de manejo das coleções para as atividades de ensino, pesquisa e extensão.

PALAVRAS-CHAVE: gestão de acervos, arqueologia, reserva técnica, conservação preventiva.

\section{ABSTRACT}

This paper presents the procedure manual used for Laboratory of Teaching and Researching in Anthropology and Archaeology of the Federal University of Pelotas (LEPAARQ-UFPEL), concerning to the management of collections deposited in the Technical Reserve (TR) safeguarded in this institution. The management procedures of the collections involved, since the ingress in the LEPAARQ's environment, actions related to the curative steps (cleaning, marking, packing, storage, database, and documentation), as well as the managing procedures of the collections for teaching, researching and extensionist activities.

KEYWORDS: management of collections, archeology, technical reserve, preventive conservation.

\footnotetext{
1 Professor do Departamento de Antropologia e Arqueologia e do Programa de Pós-graduação em Antropologia da Universidade Federal de Pelotas. Professor do Programa de Pós-graduação em Patrimônio Cultural da Universidade Federal de Santa Maria. Coordenador do Laboratório de Ensino e Pesquisa em Antropologia e Arqueologia (LEPAARQ/UFPel). Pesquisador do CNPq, nível 2. E-mail: milheirarafael@gmail.com.

${ }^{2}$ Arqueóloga da Universidade Federal de Pelotas. Pesquisadora do LEPAARQ. E-mail: lucipic@hotmail.com.

3 Professora do Curso de Conservação e Restauro da Universidade Federal de Pelotas. Pesquisadora do LEPAARQ. Doutoranda pelo Programa de Pós-graduação em Memória e Patrimônio da UFPEL. E-mail: caldaskaren@gmail.com.

${ }^{4}$ Mestranda do Programa de Pós-graduação em Antropologia e Arqueologia na Universidade Federal de Minas Gerais. Graduada em Conservação e Restauração de Bens Culturais Móveis na Universidade Federal de Pelotas. E-mail: paulabado@hotmail.com.
}

\begin{tabular}{|l|l|l|l|l|l|l|} 
(C) Rev. Arqueologia Pública & Campinas, SP & v.11 & n.2 & p. 25 & Novembro/2017 & ISSN 2237-8294
\end{tabular}




\section{ARTIGO}

Revista de Arqueologia Pública

\section{INTRODUÇÃO}

O manual de procedimentos adotados pelo Laboratório de Ensino e Pesquisa em Antropologia e Arqueologia da Universidade Federal de Pelotas (LEPAARQ-UFPEL), relativo ao gerenciamento das coleções depositadas na Reserva Técnica (RT) sob salvaguarda desta instituição ${ }^{5}$, visa apresentar, sob o conceito da Conservação Preventiva (CP), o gerenciamento de suas coleções desde a entrada no ambiente do LEPAARQ até as atividades de ensino, pesquisa e extensão. Envolve, portanto, ações na etapa de curadoria (higienização, marcação, acondicionamento, armazenamento, elaboração de banco de dados e documentação), bem como procedimentos de manejo das coleções para as atividades de pesquisa e extensão.

Desde sua criação, no ano de 2001, o LEPAARQ tem passado por uma série de experiências que visam à qualificação do espaço da RT e dos procedimentos de curadoria e salvaguarda em geral. Após o ano de 2014, a inserção de profissionais da Conservação e Restauração no grupo de pesquisadores do LEPAARQ incorporou uma série de conceitos e procedimentos da Conservação Preventiva. Deu-se início a um Diagnóstico de Conservação Preventiva das coleções arqueológicas, em que se pode destacar ações preocupadas com o registro de temperatura e umidade do ambiente da RT e do LEPAARQ em geral. Além disso, ocorreram mudanças de procedimentos de salvaguarda dos objetos e diagnóstico de danos às coleções, o que gerou, por sua vez, uma linha de pesquisa em particular. É importante destacar que o manual aqui apresentado se configura em um documento dinâmico, visto que novas práticas são incorporadas permanentemente no gerenciamento do acervo, para fins de sua qualificação.

O LEPAARQ foi criado oficialmente no ano de 2001. Ele integra a estrutura do Instituto de Ciências Humanas (ICH) da Universidade Federal de Pelotas (UFPel) e é um laboratório constituído de duas áreas do conhecimento, Antropologia e Arqueologia, podendo atuar em perspectiva interdisciplinar em diversas áreas afins, nomeadamente as áreas de História, Museologia, Conservação e Restauração, Patrimônio Cultural e Memória Social. Além de projetos em diferentes áreas do conhecimento, o LEPAARQ é um espaço de atuação de pesquisadores, docentes, discentes e técnicos de diferentes cursos da UFPEL, tanto em nível de graduação quanto de pós-graduação, assim como de pesquisadores provenientes de outras instituições de ensino superior.

\footnotetext{
${ }^{5}$ Este texto é uma versão resumida do manual. O documento na sua versão integral pode ser acessado pelo site do LEPAARQ: http://wp.ufpel.edu.br/lepaarq/.
} 


\section{A RESERVA TÉCNICA DO LEPAARQ}

O LEPAARQ localiza-se nas dependências do Instituto de Ciências Humanas da Universidade Federal de Pelotas e conta com ampla sala no térreo do prédio, que mede $37,70 \mathrm{~m}^{2}$. Esta sala abriga o espaço de curadoria, contendo pias de água corrente, secadores, mesa e prateleiras. O espaço conta também com uma RT propriamente dita, com 26,00 $\mathrm{m}^{2}$, cujo espaço é delimitado por uma grade que possibilita controle de acesso e segurança. Atualmente a RT conta com outra área gradeada ao lado desta sala, com 16,10 $\mathrm{m}^{2}$, e para onde a RT poderá ser expandida, caso necessário (Figuras 1 e 2). Além disso, o LEPAARQ conta com dois mezaninos, sendo um com $38,00 \mathrm{~m}^{2}$, que abriga a área administrativa e uma sala de estudos, e outro mezanino, com $57,80 \mathrm{~m}^{2}$, onde se situa a sala de análise, com mobiliário adequado a esta atividade, a Coleção de Referência Osteológica e a Mapoteca.

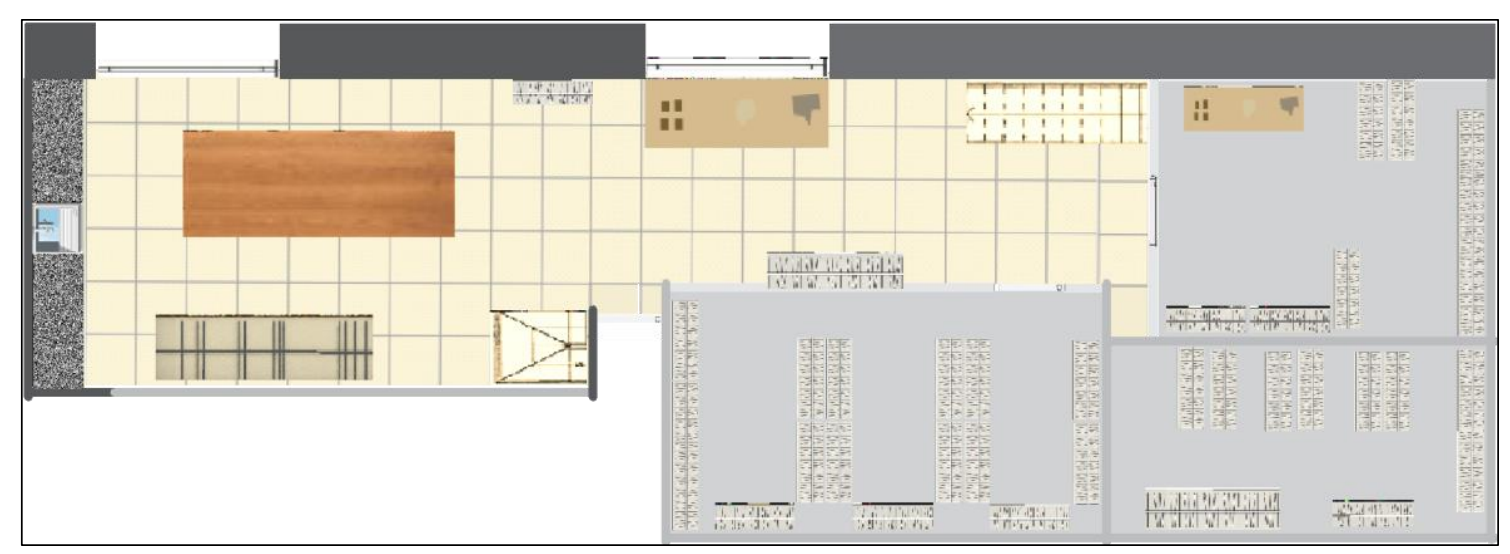

Figura 1: Croqui do espaço térreo do LEPAARQ. Fonte: AGUIAR, 2016.
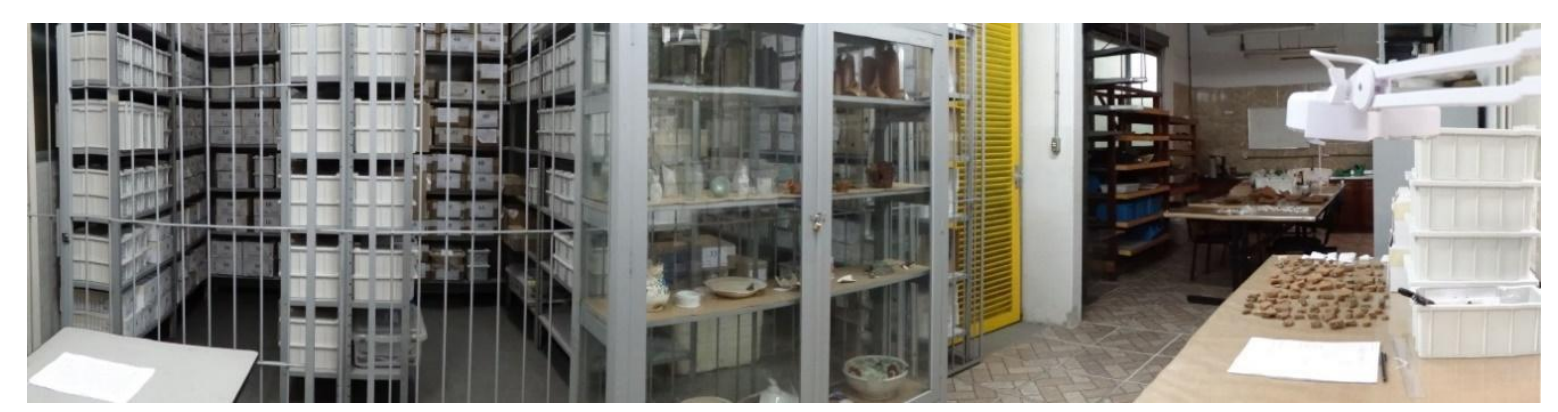

Figura 2: Visão panorâmica da sala térrea contendo a Reserva Técnica, área de higienização e curadoria, mostrando a integração dos espaços do laboratório. Foto: Ana Batista. Acervo LEPAARQ, 2014. 


\section{ARTIGO}

\section{Revista de Arqueologia Pública}

Seguindo procedimentos que visam à Conservação Preventiva, vêm sendo realizadas ações que buscam qualificar o espaço de guarda numa perspectiva de aprofundar o conhecimento a respeito das características do laboratório, desde os objetos que abriga até o ambiente em que está inserido.

A fase inicial do trabalho de Conservação Preventiva no laboratório está associada à readequação da Reserva Técnica e à alimentação do banco de dados pré-existente com as informações sobre o estado de conservação das coleções. A primeira tarefa envolveu a transferência de todas as coleções para novas embalagens de acondicionamento, substituindo as antigas caixas de papelão (material que além de ácido, constitui-se como um atrativo para roedores e outras pragas) por caixas de polipropileno, material considerado inerte e indicado para a armazenagem de artefatos arqueológicos (Figura 3).

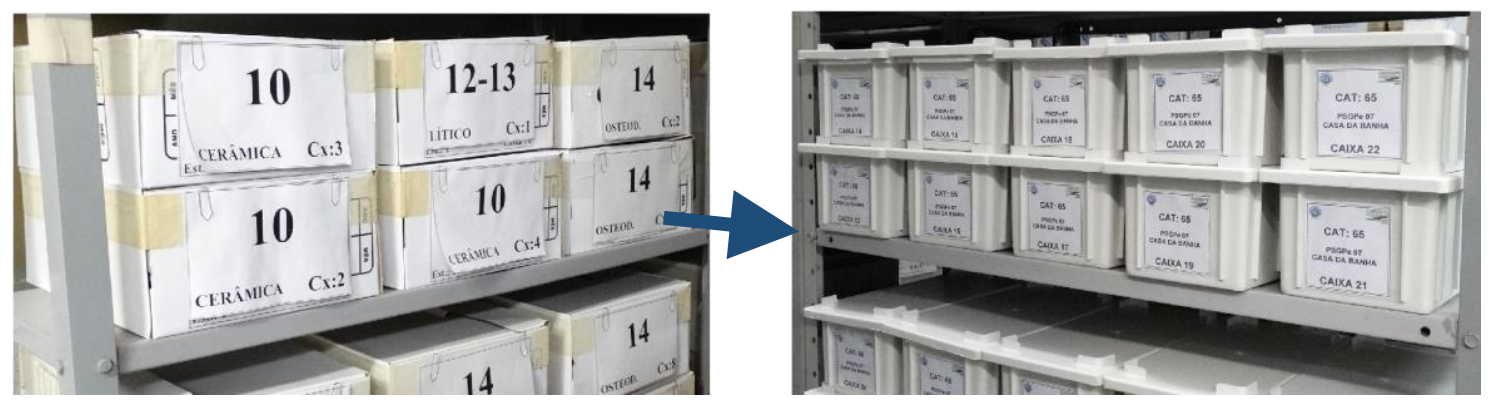

Figura 3: Transição de caixas de papelão por caixas de polipropileno, em busca de um melhor acondicionamento das coleções na reserva técnica. Foto: Paula Aguiar. Acervo LEPAARQ, 2014.

O monitoramento ambiental no acervo é outra atividade que vem sendo realizada. Essa ação envolve o uso de um datalogger ${ }^{6}$ para registrar dados sobre os fatores de temperatura e de umidade relativa, os quais vêm sendo medidos desde o ano de 2014, ininterruptamente. Uma etapa piloto desse empreendimento iniciou-se no final do outono do ano de 2014 e transcorreu continuamente até o início do inverno do mesmo ano, totalizando 3 meses. Nesse primeiro momento, a medição indicou certa estabilidade nos padrões de temperatura: registrou uma média de $18^{\circ} \mathrm{C}$ para o período, com variações menores que $5^{\circ} \mathrm{C}$. Esse resultado preliminar suscitou otimismo, pois segundo esclarece Michalski (2009), de uma maneira geral tais taxas não significam riscos para as tipologias de materiais que compõem o acervo do LEPAARQ. As taxas de umidade relativa, por sua vez, indicaram poucas oscilações de um mês para o outro (em torno de $6 \%$ ), contudo, durante o período de

\footnotetext{
${ }^{6}$ Datalogger AKSO, de Temperatura e Umidade com Conexão USB Direta - AK172. Dados disponíveis em: http://www.akso.com.br/produtos/controle-de-qualidade/dataloggers--registradores?gclid=CLiG4ebWOMECFUMV7Aod1jQAwQ. Acesso em: 28/10/2014.
}

\begin{tabular}{|l|l|l|l|l|l|l|} 
(C) Rev. Arqueologia Pública & Campinas, SP & v.11 & n.2 & p. 28 & Novembro/2017 & ISSN 2237-8294
\end{tabular}




\section{ARTIGO}

\section{Revista de Arqueologia Pública}

medição, os índices mantiveram-se acima do máximo aceitável para instituições de guarda (UR $=60 \%$ ), com o pico de $90,06 \%$ em junho de 2014. Ao longo dos últimos três anos, os resultados têm se mantido nos mesmos níveis, ou seja, com temperaturas médias de $20^{\circ} \mathrm{C}$ e umidade relativa de 75,68\% para o período de 12 meses. No ano de 2017, por exemplo, entre os dias 10 de julho e o dia 17 de agosto os dados coletados foram: temperatura média de $17,98 \stackrel{\circ}{ } \mathrm{C}$ e umidade relativa média de $75,09 \%$ (Figura 4).

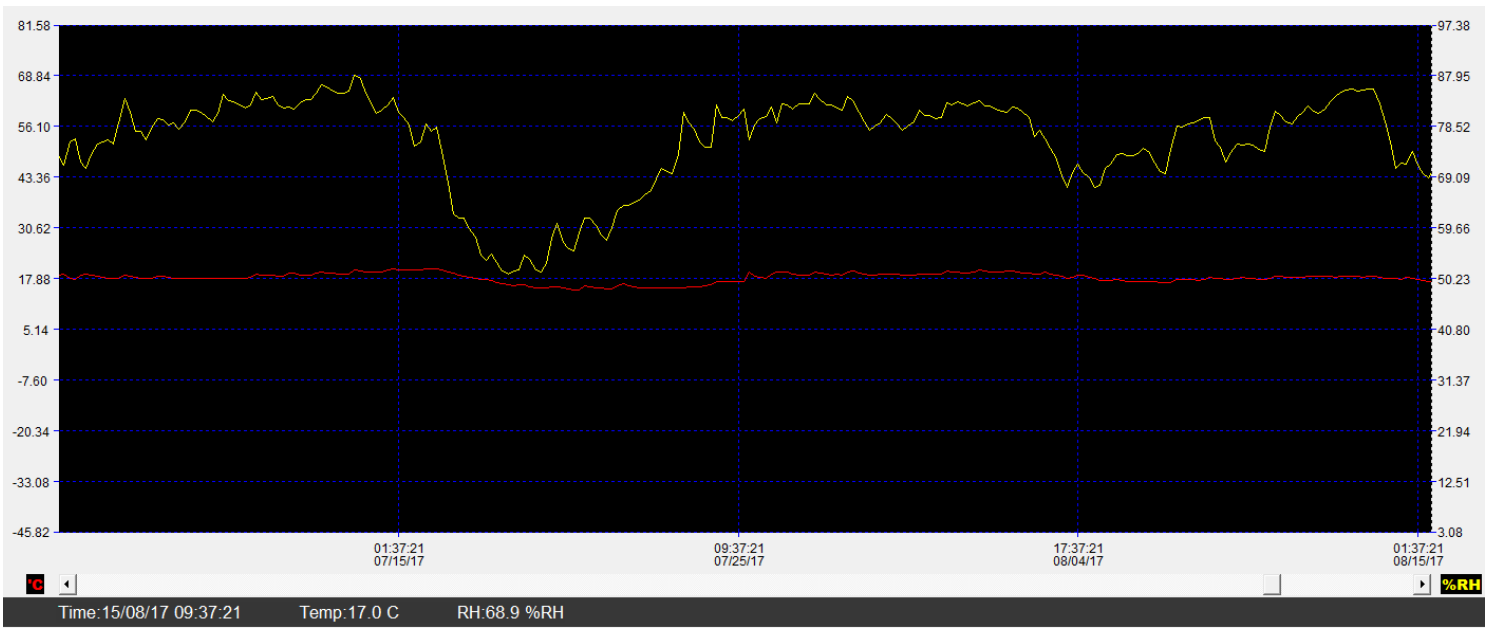

Figura 4: Registro medido com dattaloger indicando homogeneidade de temperatura e oscilação de umidade no ambiente da RT entre os dias 10 de julho e o dia 17 de agosto.

Em verdade, as altas taxas de umidade relativa são características das condições climáticas da cidade de Pelotas, cuja média anual está em torno de 80,7\% (EAP, 2014).

Tal constatação configura-se como uma problemática de conservação para os gestores do LEPAARQ, especialmente porque alguns itens da coleção reagem facilmente frente a essa situação de risco: os materiais metálicos, por exemplo, podem apresentar uma rápida corrosão (MICHALSKI, 2009), e as peças ou partes de peças que sustentam elementos de natureza orgânica são suscetíveis à biodegradação (CALLOL, 2013). Em contrapartida, a estratégia de estabilização ambiental mais rápida e corriqueira envolveria a implantação de aparelhos de ar condicionado e desumidificadores, empreendimento cuja viabilidade vem sendo estudada. 


\section{POLÍTICA DE ENDOSSO INSTITUCIONAL, EMPRÉSTIMO DE MATERIAIS ARQUEOLÓGICOS E UTILIZAÇÃO DA RT}

\section{POLÍTICA DE ENDOSSO INSTITUCIONAL}

Até o ano de 2011, os endossos institucionais solicitados por empresas de consultoria ambiental e por pesquisadores tanto da UFPEL quanto de outras IES respeitavam um trâmite que passava apenas pela avaliação e aceite da Direção do Instituto de Ciências Humanas da UFPEL. No ano de 2011, foi instituída a portaria 067/2011 do ICH, que regulamenta a concessão de Endosso Institucional pelo Instituto de Ciências Humanas (Apêndice 2) para a realização de pesquisas arqueológicas, nos termos em que dispõe a Lei $n$. . 3.924, de 26 de julho de 1961 e a Portaria IPHAN 07, de 01 de dezembro de 1988. Por meio desta portaria, o LEPAARQ-UFPEL passou a ter um controle mais adequado das políticas de endosso da instituição, dando maior transparência pública ao processo. $O$ LEPAARQ, desde o ano de 2002, endossou 93 projetos de pesquisa, sendo 88 referentes a processos de licenciamento ambiental e 05 referentes a processos de arqueologia acadêmica dos professores e professoras da UFPEL.

Além disso, o LEPAARQ criou um regramento interno para receber coleções endossadas na forma do Termo de Responsabilidade para Concessão de Endosso Institucional'. Esse termo de responsabilidade é anexado a todo e qualquer processo de solicitação de endosso para que seja conhecido pelo responsável pelo projeto e/ou pelo empreendedor solicitante, sendo necessário que estes deem vistas, comprometendo-se com o cumprimento de suas cláusulas.

\section{UTILIZAÇÃO DA RESERVA TÉCNICA}

A reserva técnica do $\mathrm{ICH}$, por estar ligada diretamente a um laboratório de ensino e pesquisa, já tem determinadas, desde sua origem, suas finalidades primeiras. O ensino e a pesquisa são, portanto, sua causa e seu fim. Como consequência dessas atividades de ensino e pesquisa realizadas pela equipe do LEPAARQ, foram incorporadas também atividades de extensão, principalmente na forma de projetos de Educação Patrimonial.

Em dezesseis anos de existência, a RT, ao mesmo tempo em que foi alimentada por pesquisas arqueológicas de campo, oportunizou a realização de dezenas de estudos teóricos que se configuraram em trabalhos de conclusão de curso de graduação (TCC),

\footnotetext{
${ }^{7}$ Acessível no site do LEPAARQ por meio do link: http://wp.ufpel.edu.br/lepaarq/?page_id=138.
}

\begin{tabular}{|l|l|l|l|l|l|l}
\hline (C) Rev. Arqueologia Pública & Campinas, SP & v.11 & n.2 & p. 30 & Novembro/2017 & ISSN 2237-8294
\end{tabular}


dissertações de mestrado e teses de doutorado. Os estudos realizados a partir de diferentes coleções também resultaram em incontáveis publicações, tanto de artigos em revistas especializadas como de livros, além de propiciar a participação de muitos alunos e professores em congressos, seminários, encontros nacionais e internacionais não só da área de arqueologia, mas também de áreas afins.

Somando-se a isso, materiais que compõem a RT são sistematicamente utilizados em exposições de arqueologia e de arte, organizadas por diferentes instituições. Em nenhum caso é cobrado valor financeiro para o uso dos materiais, sendo apenas asseguradas as condições de segurança material no transporte e exposição. Também não é cobrado nenhum valor financeiro para o uso de imagens das peças, visto que o entendimento da instituição é que se tratam de materiais públicos.

\section{PROCEDIMENTOS GERAIS DE CURADORIA E DOCUMENTAÇÃO DAS COLEÇÕES ARQUEOLÓGICAS SOB GUARDA DO LEPAARQ}

\section{AS COLEÇÕES ARQUEOLÓGICAS}

Primeiramente, é preciso definir o que compõe uma coleção arqueológica. As coleções arqueológicas são compostas de materiais exumados de sítios arqueológicos, seja por meio de pesquisas arqueológicas seja por meio de coletas fortuitas. O tipo de coleta (pesquisa ou coleta fortuita) influencia enormemente a quantidade de informações disponíveis sobre os materiais e, obviamente, a documentação produzida.

As coleções arqueológicas podem ser compostas de quantidade e tipologia variadas de materiais e ingressam na Reserva Técnica por três diferentes meios: 1) doações de membros da comunidade local; 2) projetos de pesquisa acadêmica e 3) endosso institucional. Cada um destes meios requer procedimentos de curadoria diferenciados, os quais serão genericamente descritos a seguir.

I. Doações de membros da comunidade local:

Há, atualmente, 28 catálogos no LEPAARQ que foram provenientes de doações de membros da comunidade local. As peças fruto de doações ingressam na Reserva Técnica, na maioria das vezes, sem documentação de campo ou laboratório. As informações limitamse apenas ao nome do proprietário - que dá nome à coleção - e sua eventual localização. Por serem objetos já coletados fora de contexto, as peças já ingressam na RT higienizadas 


\section{ARTIGO}

\section{Revista de Arqueologia Pública}

e são apenas marcadas com numeração de catálogo, acondicionadas em caixa apropriada e guardadas.

II. Projetos de pesquisa acadêmica:

As pesquisas acadêmicas geraram até hoje 78 coleções provenientes dos seguintes projetos:

- $\quad$ Projeto LEPAARQ - Salvamento Arqueológico na Área Urbana de Pelotas-RS - praça Coronel Pedro Osório, Casa da Banha e Casas 2, 6 e 8 - $\quad$ Projeto de Mapeamento Arqueológico de Municípios da Região Sul do Rio Grande do Sul (Aceguá, Arroio Grande, Bagé, Candiota, Capão Do Leão, Cerrito, Herval, Hulha Negra, Pedras Altas, Pedro Osório, Pinheiro Machado e Piratini) - Processo Administrativo 01512.000192/2005-60 Portaria n 125 de 11 de abril de 2007

- $\quad$ Projeto LEPAARQ - Mapeamento Arqueológico de Pelotas e região (São Lourenço do Sul, Capão do Leão, Morro Redondo, Turuçu e Arroio do Padre).

- $\quad$ Projeto LEPAARQ - Arqueologia e História Indígena do Pampa: Estudo das populações pré-coloniais na bacia hidrográfica da Laguna dos Patos e Lagoa Mirim

III. Endosso Institucional:

Até o momento, estão registradas no livro de catálogo 53 coleções provenientes de endosso institucional, sendo que alguns desses números estão reservados, ou seja, foram informados aos empreendedores para serem usados no inventário do material, o qual ainda não foi entregue ao LEPAARQ.

Cada coleção recebe uma numeração corrente (número de tombo), respeitando a cronologia de entrada na RT. Esta numeração compõe-se em um livro de catálogo que parte da coleção 001 (José Pedro Legemann 01), coletada no ano de 2000, até a atual última coleção 159 (Camping II), proveniente de escavação feita no ano de 2017. A coleção de um sítio arqueológico pode, eventualmente, ser distribuída em mais de um número de catálogo, quando tal é fruto de mais de uma campanha de escavação em datas diferentes. Esse é o caso do sítio Totó, por exemplo, com catálogos 52 (prospecção no ano de 2006), 66 e 70 (escavações em março e julho de 2007) e 97 (escavação no ano de 2010). 


\section{Revista de Arqueologia Pública}

Genericamente, pode-se dizer que a forma como foi sendo gerada a documentação dessas coleções em campo e em laboratório reflete o amadurecimento teórico-metodológico dos pesquisadores da instituição. Em linhas gerais, a documentação foi sendo cada vez mais detalhada com o passar do tempo.

\section{DOCUMENTAÇÃO}

O LEPAARQ reúne, organiza, preserva e disponibiliza para pesquisadores e público em geral a documentação relativa às coleções que gerencia. Trata-se, em geral, de diários de campo, desenhos, croquis e fotografias de materiais e coleções exumadas em campo por meio de pesquisa. Em laboratório, a documentação é composta de fichas, etiquetas, desenhos, fotografias, tabelas de análise etc.

Toda a documentação é catalogada e numerada em consonância com a coleção à qual se refere, sendo guardada em formato físico e/ou digital, a depender do tipo de material. Entende-se que a documentação é parte integrante da coleção arqueológica em si, sendo uma premissa à associação entre materiais arqueológicos e a documentação gerada sobre eles.

Como método de organização, o LEPAARQ mantém dois "Livros" de registro em formato físico, um para registro de sítios arqueológicos e outro para registro de "Catálogos" e um arquivo documental onde são guardados todos os materiais referentes a cada coleção. Além disso, as informações contidas nos livros e no arquivo são reproduzidas (digitadas ou escaneadas) e organizadas em arquivos digitais. Estes arquivos digitais seguem a mesma ordem da documentação física do laboratório e neles também é mantida toda informação digital produzida nas pesquisas, como fotografias, imagens, tabelas, fichas etc. (Figura 5). 


\section{Revista de Arqueologia Pública}

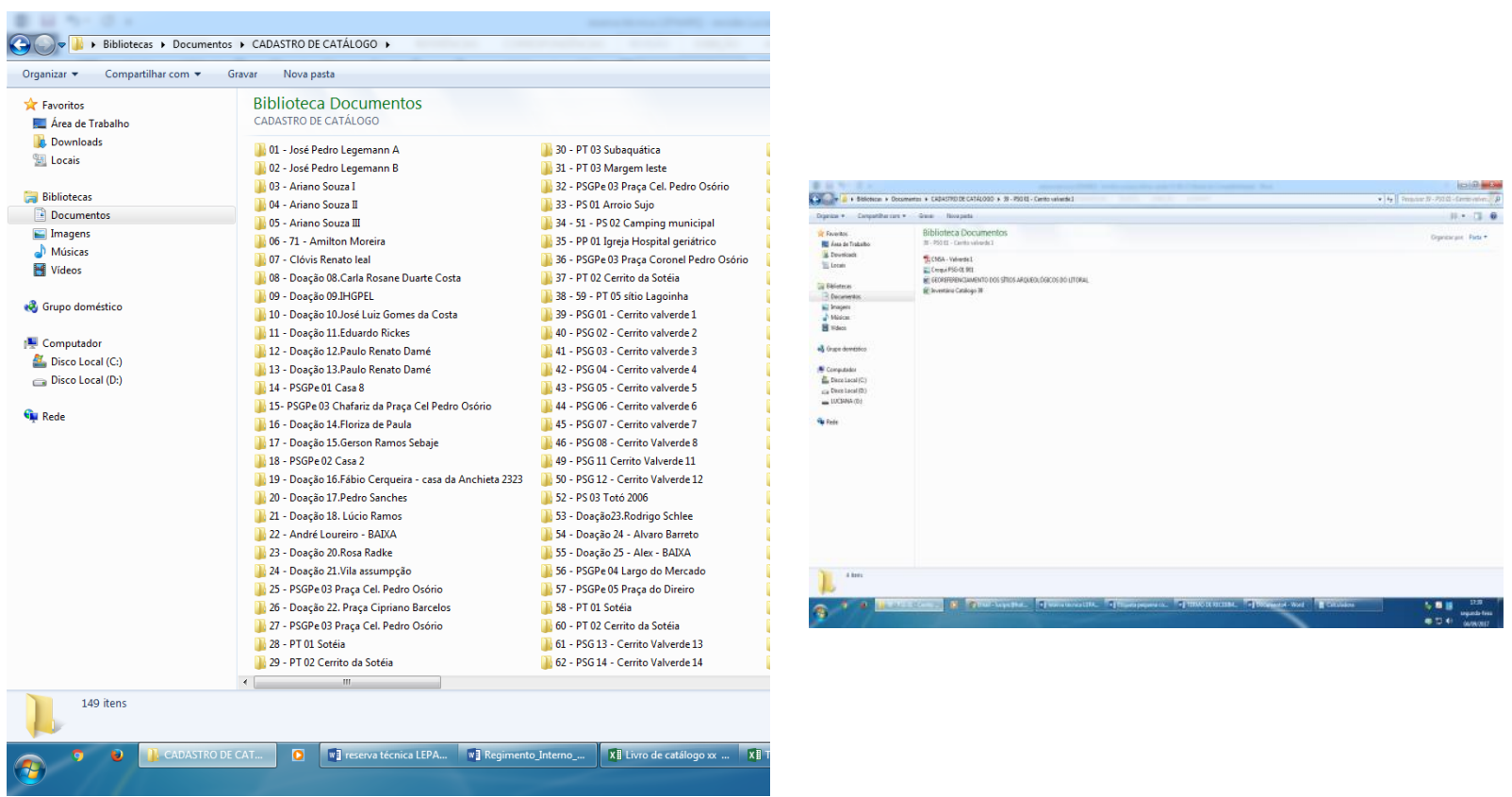

Figura 5: Imagem ilustrativa da organização dos arquivos digitais no sistema do LEPAARQ.

\section{REGISTRO DE SÍTIOS ARQUEOLÓGICOS}

O registro dos sítios arqueológicos é realizado em duas etapas, a primeira no Livro de Registros do LEPAARQ e a segunda no sistema de Registros de Sítios do IPHAN (CNSA). Na medida em que os sítios arqueológicos são identificados, eles são nomeados a partir de um sistema interno do LEPAARQ, que considera a localização do sítio em relação à principal bacia hidrográfica regional. Assim, tem-se um sistema de siglas que identifica 0 local, por exemplo PSG, em que a sigla indica que o sítio se localiza na bacia hidrográfica da laguna dos Patos $(P)$ e na área do Canal São Gonçalo (SG). Como vários sítios podem estar localizados na mesma área, usa-se um número para diferenciá-los. Dessa forma temos o nome do sítio formado por uma sigla alfa numérica, por exemplo, o PSG 06, que indica o sexto sítio registrado na área do Canal São Gonçalo. Além disso, costuma-se usar um segundo nome que se refere à forma popular pela qual o sítio é conhecido. No exemplo acima, temos o Cerrito Valverde 06, nome que indica a localidade (Balneário Valverde) onde está o sítio. 


\section{ARTIGO}

Revista de Arqueologia Pública

\section{REGISTRO DE CATÁLOGOS}

No LEPAARQ, convencionou-se chamar de Catálogo o conjunto dos materiais arqueológicos de uma mesma campanha de escavação ou de coleta, de um sítio ou de uma doação, ou seja, uma coleção. Cada coleção, ao chegar no laboratório, é registrada no Livro de Catálogo.

O número de Catálogo é atribuído pela ordem cronológica de chegada do material ao laboratório. Até o momento, estão registradas 159 entradas, sendo que ao longo dos anos, algumas dessas coleções foram retiradas da Reserva Técnica do laboratório por diversos motivos e por isso foi dado baixa do registro no livro.

No Livro de Catálogo são informados o nome do sítio - conforme tabela de siglas ou número da doação, local, município, tipo de sítio (histórico ou pré-histórico), data da campanha e observações (Figura 6).

\begin{tabular}{|c|c|c|c|c|c|c|c|}
\hline Catálogo & Código & $\begin{array}{l}\text { Nome do Sítio } \\
\text { ou Doador }\end{array}$ & Local & Município & Tipo & Data & Observação \\
\hline 1 & Doação 01 & $\begin{array}{l}\text { José Pedro } \\
\text { Legemann A }\end{array}$ & Barra Falsa & Rio Grande & Dunas Pré-hist. & $23 / 10 / 2000$ & $\begin{array}{c}\text { Coleta superficial sistemática realizada no sítio LS-01 } \\
\text { (registro LEPAN) José Pedro Legemann A durante o } \\
\text { curso de Introducão a Arqueologia. }\end{array}$ \\
\hline 2 & Doação 02 & $\begin{array}{l}\text { José Pedro } \\
\text { Legemann B }\end{array}$ & Barra Falsa & Rio Grande & Dunas Pré-hist. & $23 / 10 / 2000$ & $\begin{array}{c}\begin{array}{c}\text { Coleta superficial sistemática realizada no sitio LS-01 } \\
\text { (registro LEPAN) José Pedro Legemann B durante o curso } \\
\text { de Introdução a Arqueologia. }\end{array} \\
\end{array}$ \\
\hline 3 & Doação 03 & Ariano Souza I & Barra Falsa & Rio Grande & Dunas & $23 / 10 / 2000$ & $\begin{array}{c}\begin{array}{c}\text { Coleta superficial sistemática realizada no sitio LS-02 } \\
\text { (registro LEPAN) Ariano Souza I durante o curso de } \\
\text { Introdução a Arqueologia. }\end{array} \\
\end{array}$ \\
\hline 4 & Doação 04 & Ariano Souza II & Barra Falsa & Rio Grande & Dunas & $23 / 10 / 2000$ & $\begin{array}{l}\text { Coleta superficial sistemática realizada no sitio LS-02 } \\
\text { (registro LEPAN) Ariano Souza II durante o curso de } \\
\text { Introducão a Arqueologia. }\end{array}$ \\
\hline 5 & Doação 05 & Ariano Souza III & Barra Falsa & Rio Grande & Dunas & $23 / 10 / 2000$ & $\begin{array}{l}\text { Coleta superficial sistemática realizada no sitio LS-02 } \\
\text { (registro LEPAN) Ariano Souza III durante o curso de } \\
\text { Introducão a Arqueologia. }\end{array}$ \\
\hline $06 / 71$ & $\begin{array}{c}\text { Doação } 06 / \\
\text { Doação } 29\end{array}$ & Amilton Moreira & Barra Falsa & Rio Grande & Dunas & $\begin{array}{l}23 / 10 / 2000 \text { e } \\
2007\end{array}$ & $\begin{array}{l}\text { Coleta superficial sistemática realizada no sitio LS-03 } \\
\text { (registro LEPAN) Amiltom Moreira durante o curso de } \\
\text { Introducão a Arqueologia. }\end{array}$ \\
\hline 7 & Doação 07 & Clóvis Renato Leal & Col. Sto. Antônio & Pelotas & - & $24 / 11 / 2000$ & $7^{\circ}$ distrito/ cerâmica - lítico \\
\hline 8 & Doação 08 & $\begin{array}{c}\begin{array}{c}\text { Carla Rosane Duarte } \\
\text { Costa }\end{array} \\
\end{array}$ & Clube Campestre & Capão do Leão & Dunas & $06 / 07 / 2001$ & Zoolito - lítico \\
\hline 9 & Doação 09 & IHGPEL & Diversos & Pelotas & - & 2001 & Cerâmica - Lítico - Zooarqueológico \\
\hline 10 & Doação 10 & $\begin{array}{c}\text { José Luiz Gomes da } \\
\text { Costa }\end{array}$ & - & Arroio do Padre & Campo Aberto & $15 / 04 / 2002$ & Urna - cerâmica \\
\hline 11 & Doação 11 & Eduardo Rickes & Cascata & Pelotas & Campo Aberto & $15 / 04 / 2002$ & Percutor \\
\hline 12 & Doação 12 & Paulo Renato Damé & - & Canguçu & - & $10 / 07 / 2000$ & Boleadeiras - Enxó \\
\hline 13 & Doação 13 & Paulo Renato Damé & Vale Rio Camaquã & \begin{tabular}{|c|} 
Encruzilhada do \\
Sul
\end{tabular} & - & $10 / 07 / 2000$ & Boleadeiras - Peso de rede \\
\hline 14 & PSGPe 01 & Casa 8 & $\begin{array}{c}\text { Pç. Cel. Pedro } \\
\text { Osório, n8 }\end{array}$ & Pelotas & Histórico & Campanha 2002 & $\begin{array}{c}\text { Salvamento arqueológico em obra de restauro - } 49 \\
\text { setores }\end{array}$ \\
\hline 15 & PSGPe 03 & Chafariz & $\begin{array}{c}\text { Praça Cel. Pedro } \\
\text { Osório }\end{array}$ & Pelotas & Histórico & $28 / 06 / 2002$ & $\begin{array}{l}\text { Salvamento em obra de restauro no Chafariz da Praça } \\
\text { Cel. Pedro Osório. }\end{array}$ \\
\hline 16 & Doação 14 & Floriza de Paula & Ilha da Feitoria & Pelotas & $\begin{array}{l}\text { Pré-histórico/ } \\
\text { Histórico }\end{array}$ & $22 / 07 / 2002$ & Cerâmica - Louça \\
\hline 17 & Doação 15 & $\begin{array}{l}\text { Gerson Ramos } \\
\text { Sebaje }\end{array}$ & $\begin{array}{l}\text { Morro Alto da } \\
\text { Cruz }\end{array}$ & Pelotas & Pré-histórico & $03 / 12 / 2002$ & Boleadeira - Cerâmica \\
\hline
\end{tabular}

Figura 6: Imagem da 1aㅡ folha do livro de registro de catálogos. Fonte: LEPAARQ. 


\section{ARTIGO}

Revista de Arqueologia Pública

\section{PROCEDIMENTOS CURATORIAIS}

Em relação à prática de curadoria, em linhas gerais, tem-se que ao adentrarem o laboratório, as peças arqueológicas provenientes do campo são separadas por lotes conforme a orientação de campo, o que depende da coordenação do projeto e da metodologia de escavação ou prospecção (quadrícula, setor de escavação, poço teste, sítio). Após a organização por lotes, o material passa à higienização - que depende das preocupações do projeto e do tipo de material - e, em seguida, à triagem. A triagem é um momento importante, já que é quando se tem a oportunidade de descartar materiais considerados irrelevantes ao contexto, por exemplo, material moderno em um sítio précolonial, carvão evidentemente recente e isolado, sedimentos e rochas sem marcas de uso e sem contexto de antropização (seixos de rio e rochas não lascadas, por exemplo).

\section{HIGIENIZAÇÃO}

A limpeza/higienização dos materiais é feita levando em conta a sua natureza (matéria prima), o local de onde foi exumado (tipo de solo e condições), o seu estado de conservação e a finalidade da análise a ser feita nos materiais. Aqueles artefatos que forem selecionados para análise físico-química passam por um procedimento específico considerando os protocolos de análise determinados para este fim. Cada categoria de material exige uma metodologia específica para limpeza:

- Materiais orgânicos: na categoria de materiais orgânicos temos os ossos animais, os ossos humanos e os vegetais (sementes). Se for retirada de solo úmido, a maioria destes materiais é limpa com água corrente. Para os ossos humanos, recomenda-se o uso de escova macia e úmida. No caso de retirada de locais secos e com solo mais arenoso, situação em que não há muita aderência de resíduos ao material, não deverá ser utilizada água, apenas escovas macias.

- Outros materiais orgânicos: podem ser considerados materiais orgânicos os tecidos, o couro, a madeira e o papel. Estes materiais devem ser limpos apenas com escovas macias e secas.

- Materiais inorgânicos: nesta categoria estão cerâmicas indígenas, louças e porcelanas, vidros, grés e plástico. A limpeza destes materiais geralmente é feita com 
água, utilizando escovas macias e sem fricção que possa danificar as peças. No entanto, é necessária boa observação da peça antes da realização da limpeza, a fim de se certificar que não existam detalhes decorativos que possam ser danificados com o uso de água, como pintura sobre o esmalte, frisos dourados etc. No caso de serem identificados esses detalhes decorativos, deve-se proceder à limpeza apenas com escova macia e seca.

- Outros materiais inorgânicos: neste grupo estão basicamente os materiais compostos de diversas ligas metálicas. Estes materiais recebem limpeza mecânica para retirada do sedimento solto, com escova, sem nenhum contato com materiais químicos ou água.

Pode ser ainda considerado como higienização o processo de flotação, por meio do qual o sedimento é separado dos materiais de importância arqueológica. O sedimento, após flotação, é descartado, guardando-se apenas os materiais como ossos, lascas, carvões e botânicos, cerâmicas em pequenas proporções e tamanhos, os quais, por sua vez, são triados e catalogados em separado para análises específicas.

\section{INVENTÁRIO E REGISTRO DE PEÇAS}

O inventário de peças constitui-se no registro individual de cada peça ou fragmento que compõe uma coleção. Para isso, cada peça recebe um número que é inserido em uma tabela e ao qual são relacionadas informações individuais da peça, como procedência, categoria, tipologia, descrição, estado de conservação e localização dentro da Reserva Técnica.

O número atribuído a cada peça é um conjunto formado por três partes, em que cada parte representa, respectivamente, o número de catálogo, o número de lote e o número da peça dentro da coleção.

Conforme já descrito anteriormente, o número de lote pode se referir a uma quadrícula, um setor de escavação, um poço teste ou ao próprio sítio, dependendo do sistema organizacional de campo.

Ao mesmo tempo em que é feita a numeração, é preenchida a tabela onde são relacionadas todas as informações sobre cada uma das peças, incluindo a classificação quando possível - e a quantificação. Esta tabela é organizada a partir do lote, conforme exemplo na tabela 01. 


\section{Revista de Arqueologia Pública}

A numeração sempre foi transcrita com tinta nanquim para a superfície interna da peça previamente preparada com uma camada de esmalte incolor. No entanto, a partir do ano de 2017, foi adotado, como base, o uso de resina acrílica Paraloid a 15\% em Xilol, preferivelmente em um local que acarrete o menor impacto no processo de análise (Figura 7). A aplicação do Paraloid como verniz de isolamento está sendo utilizada em substituição ao esmalte de unhas incolor anteriormente empregado. O Paraloid é uma resina sintética amplamente utilizada em conservação-restauração e o não-uso de esmalte para unhas é uma recomendação ${ }^{8}$ do CIDOC-ICOM (Comitê para a Documentação do Conselho Internacional de Museus), instituição cujas diretrizes internacionais orientam as ações de salvaguarda dos bens culturais. Dependendo do material, a utilização do verniz faz-se obrigatória ou facultativa. Para superfícies duras e não porosas - como vidros e ligas metálicas - o verniz pode ser usado, mas para materiais duros e porosos - como madeiras, terracotas, ossos - deve ser aplicada camada sobre a peça antes e depois da inscrição da numeração com tinta nanquim branco ou preto, dependendo da cor de fundo característica do objeto. O tipo de tinta a ser usado nas inscrições não é especificado pelo CIDOC-ICOM em suas diretrizes. Nos registros do LEPAARQ, é utilizada a tinta nanquim, que, por ser à base d'água pode ser considerada um material relativamente inerte e reversível, especialmente se aplicada sobre a resina acrílica e, além disso, proporciona fácil manuseio.

${ }^{8}$ CIDOC Standards, guidelines: CIDOC Fact Sheet No. 2. 


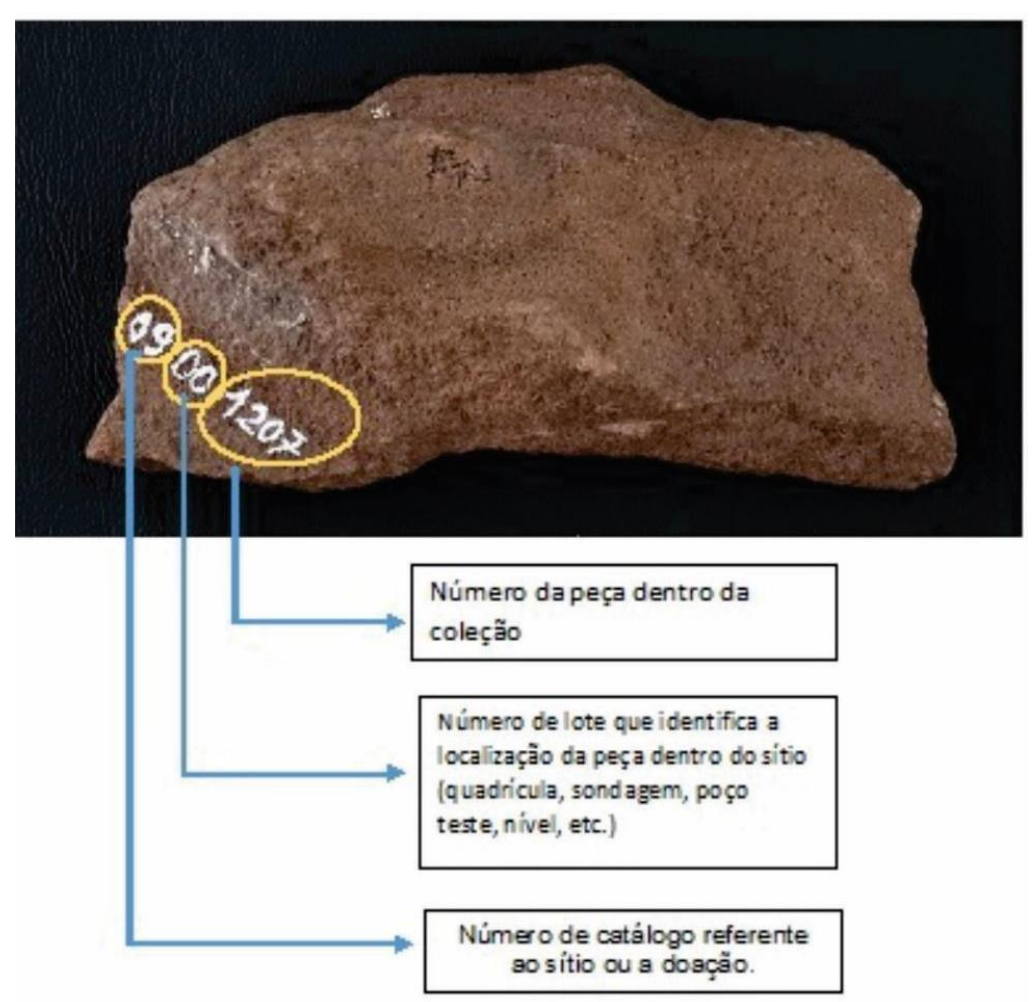

Figura 7: Processo de numeração de peças.

Fonte: LEPAARQ.

\section{ACONDICIONAMENTO}

O acondicionamento para armazenamento na Reserva Técnica é feito levando em conta a categoria dos materiais, ou seja, sua matéria prima. É possível que diversos materiais inorgânicos sejam acondicionados numa mesma caixa, contanto que entre eles não estejam peças de liga metálica. Os materiais compostos de ligas metálicas devem sempre ser armazenados separadamente. O mesmo vale para materiais orgânicos, principalmente ossos e vestígios botânicos.

Assim, cerâmicas, louças e vidros de uma mesma procedência e, portanto, com o mesmo número de lote, podem ser guardados em uma mesma caixa. Ligas metálicas, materiais líticos e elementos construtivos são guardados em caixas específicas para cada categoria. Por fim, ossos humanos, restos faunísticos, madeiras e demais categorias são guardados também em caixas específicas. É importante salientar que um mesmo lote de material pode ser guardado em diferentes caixas, pois as peças são separadas de acordo com sua categoria, medida adotada para melhor conservação dos acervos.

Como exceção a essas regras de curadoria, no que se refere à higienização, temos os sedimentos que são coletados em campo já condicionados em função de algum tipo de \begin{tabular}{|l|l|l|l|l|l|l|}
\hline (c) Rev. Arqueologia Pública & Campinas, SP & v.11 & n.2 & p. 39 & Novembro/2017 & ISSN 2237-8294 \\
\hline
\end{tabular} 


\section{ARTIGO}

Revista de Arqueologia Pública

análise em vista. Por conta disso, são coletadas quantidades de sedimentos necessárias às análises (de granulometria ou química de solos, por exemplo), raramente ultrapassando 1 kg. Após a conferência das informações de campo e eventual troca de embalagens de armazenamento, podem seguir diretamente para as análises ou podem ser guardadas para análise em momento futuro. Em caso de análise, as amostras de sedimento serão destruídas e, por isso, automaticamente descartadas da coleção. Em caso de guarda para análise futura, são acondicionadas separadamente e incluídas no final do inventário. Neste caso, quando forem enviadas para análise será dado baixa na numeração correspondente.

\section{CONSIDERAÇÕES FINAIS}

Desde sua criação em 2001, o LEPAARQ vem qualificando sua Reserva Técnica (RT) e aprimorando de modo contínuo os procedimentos de curadoria e salvaguarda do conjunto patrimonial do qual é responsável. Em constante crescimento, o acervo do laboratório passou a demandar a colaboração da área de Conservação e Restauração, o que se efetivou no ano de 2014 com a participação de equipe de profissionais que se somaram nas discussões e tomadas de decisão interdisciplinares.

Um dos resultados dessa atuação conjunta é o desenvolvimento do manual de procedimentos relativo ao gerenciamento das coleções depositadas na RT sob salvaguarda da instituição, que foi apresentado resumidamente no presente texto. Esse manual apresenta-se como forma de enfrentar um dos grandes desafios de gestão do acervo, qual seja, o de melhorar o diálogo entre todos os atores que se relacionam com os artefatos arqueológicos sob responsabilidade do LEPAARQ. Com base nos conceitos de Conservação Preventiva, o manual visa orientar o gerenciamento das coleções desde que estas são introduzidas no acervo - envolvendo, portanto, ações na etapa de curadoria -, assim como procedimentos de manejo das coleções para as atividades de ensino, pesquisa e extensão. É importante destacar o caráter dinâmico desse manual em razão da incorporação constante de novas práticas no gerenciamento do acervo para atender às mudanças e ao crescimento do conjunto de bens sob custódia da instituição.

Por fim, é importante salientar o fato de que todas essas ações visam à qualificação dos processos de conservação do acervo e decorrem do entendimento de que o trato com coleções patrimoniais exige uma atuação conjunta de várias áreas, que devem somar esforços com fins à preservação. Todas as ações que visam à conservação dos materiais arqueológicos e às informações referentes são pensadas e executadas por meio de uma política que se pode definir como "sustentável", ou seja, práticas que atendem às demandas

\begin{tabular}{|l|l|l|l|l|l|l}
\hline (C) Rev. Arqueologia Pública & Campinas, SP & v.11 & n.2 & p. 40 & Novembro/2017 & ISSN 2237-8294
\end{tabular}


de uma instituição com recursos financeiros e materiais escassos. Vale ressaltar que o objetivo do gerenciamento é preservar as coleções arqueológicas e os seus documentos, sem inviabilizar as pesquisas e o uso dessas coleções (em suas variadas finalidades) pelo cometimento de excessos curatoriais, buscando um equilíbrio que provém do bom diálogo entre profissionais das distintas áreas que atuam e pensam sobre o acervo.

\section{REFERÊNCIAS BIBLIOGRÁFICAS}

AGUIAR, Paula. Cultivo e isolamento de microrganismos presentes em cerâmicas arqueológicas e no ambiente do LEPAARQ/UFPel, na ótica da Conservação Preventiva. Trabalho de Conclusão de Curso. Universidade Federal de Pelotas, 2016.

ICOM. International Committee for Documentation. CIDOC Standards, guidelines: CIDOC Fact Sheet No. 2. S/D. Disponível em: <http://network.icom.museum/fileadmin/user_upload/ minisites/cidoc/DocStandards/CIDOC_Fact_Sheet_No_2.pdf>.

FLORÊNCIO, Sônia Rampim; CLEROT, Pedro; BEZERRA, Juliana; RAMASSOTE, Rodrigo. Educação Patrimonial: Histórico, conceitos e processos. Instituto do Patrimônio Histórico e Artístico Nacional, 2014.

CALLOL, Milagros V. Biodeterioração do patrimônio histórico documental Alternativas para eliminação e controle. Rio de Janeiro, MAST/FCRB, 2013.

MICHALSKI, S. Agent of deterioration: Incorrect Relative Humidity. Canadian Conservation Institute, Canadá, 2013. Acessado em: 24 de outubro de 2014. Online. Disponível em: <http://www.cci-icc.gc.ca/resources-ressources/agentsofdeteriorationagentsdedeterioration/chap10-eng.aspx>.

STRANG, Tom; KIGAWA, Rika. Agent of Deterioration: Combatting Pests of Cultural Property. Canadian Conservation Institute, Canadá, 2013. Acessado em: 24 de outubro de 2014. Disponível em: <http://www.cci-icc.gc.ca/resources-ressources/agentsofdeteriorationagentsdedeterioration/chap06-eng.aspx>.

EAP. Estação Agroclimatológica de Pelotas. Normas Climatológicas: estacional. Pelotas. Acesso em: 22 de outubro de 2014. Disponível em: <http://www.cpact.embrapa.br/agromet/ estacao/estacional.html>. 


\section{ARTIGO}

Revista de Arqueologia Pública

\section{TABELA 01}

Processo de numeração de peças

\begin{tabular}{|c|c|c|c|c|c|c|}
\hline Sítio & Lagoa Fragata 02 & Lagoa Fragata 02 & Lagoa Fragata 02 & Lagoa Fragata 02 & Lagoa Fragata 02 & Lagoa Fragata 02 \\
\hline Lote & 1 & 1 & 1 & 1 & 2 & 2 \\
\hline $\mathrm{N}^{\circ}$ Etiqueta & c & 2 & 3 & $\mathrm{x}$ & 1 & 1 \\
\hline Procedência & TAQ1 & TAQ1 & TAQ1 & TAQ1 & TAQ2 & TAQ2 \\
\hline Nivel & 3 & 3 & 3 & 3 & 3 & 3 \\
\hline$x$ & 58 & 58 & 15 & $x$ & 3 & 3 \\
\hline $\mathrm{Y}$ & 22 & 22 & 48 & $x$ & 35 & 35 \\
\hline$z$ & 20 & 20 & 19 & $x$ & 15 & 15 \\
\hline $\mathrm{N}^{0}$ Individual & 122.01 .013 & 122.01 .014 & 122.01 .015 & 122.01 .016 & 122.02 .017 & 122.02 .018 \\
\hline Categoria & cer. louças históricas & cer. louças históricas & cer. louças históricas & metal & metal & metal \\
\hline Tipologia & faiança fina & faiança fina & faiança fina & não identif.. & não identif.. & não identif.. \\
\hline Identifi-cação & não identif. & não identif. & não identif. & não identif. & não identif. & não identif. \\
\hline Descrição & sem decoração & sem decoração & sem decoração & não identif. & não identif. & não identif. \\
\hline Data & $10 / 12 / 2014$ & $10 / 12 / 2014$ & $10 / 12 / 2014$ & $10 / 12 / 2014$ & $10 / 12 / 2014$ & $10 / 12 / 2014$ \\
\hline Caixa & 10 & 10 & 10 & 10 & 10 & 10 \\
\hline Localização & acervo & acervo & acervo & acervo & acervo & acervo \\
\hline
\end{tabular}

